\title{
Adherence to preventive medications in asthmatic children at a tertiary care teaching hospital in Malaysia
}

This article was published in the following Dove Press journal:

Patient Preference and Adherence

18 February 2014

Number of times this article has been viewed

\author{
Adyani Md Redzuan \\ Meng Soon Lee \\ Noraida Mohamed Shah \\ Faculty of Pharmacy, Universiti \\ Kebangsaan Malaysia, Kuala Lumpur, \\ Malaysia
}

\begin{abstract}
Purpose: Asthma affects an estimated 300 million people worldwide. Poor adherence to prescribed preventive medications, especially among children with asthma, leads to increased mortality and morbidity. The purpose of this study was to assess the adherence and persistence levels of asthmatic children at the Universiti Kebangsaan Malaysia Medical Center (UKMMC), a tertiary care teaching hospital, and to determine the factors that influence adherence to prescribed preventive medications.
\end{abstract}

Patients and methods: Participants were asthmatic patients aged 18 years and younger with at least one prescription for a preventive medication refilled between January and December 2011. Refill records from the pharmacy dispensing database were used to determine the medication possession ratio (MPR) and continuous measure of gaps (CMG), measures of adherence and persistence levels, respectively.

Results: The sample consisted of 218 children with asthma from the General and Respiratory pediatric clinics at UKMMC. The overall adherence level was $38 \%(\mathrm{n}=83$; MPR $\geq 80 \%)$, and the persistence level was $27.5 \%(n=60 ; C M G \leq 20 \%)$. We found a significant association between the adherence and persistence levels $(r=0.483, P<0.01)$. The presence of comorbidities significantly predicted the adherence (odds ratio $[\mathrm{OR}]=16.21,95 \%$ confidence interval $[\mathrm{CI}]$ : 7.76-33.84, $P<0.01)$ and persistence level (OR $=2.63,95 \%$ CI: $0.13-52.79, P<0.01)$. Other factors, including age, sex, ethnicity, duration of asthma diagnosis, and number of prescribed preventive medications did not significantly affect adherence or persistence $(P>0.05)$.

Conclusion: In conclusion, the adherence level among children with asthma at UKMMC was low. The presence of comorbidities was found to influence adherence towards preventive medications in asthmatic children.

Keywords: asthma, persistence, non adherence, pediatric patients, medication possession ratio

\section{Introduction}

Asthma is a chronic inflammatory disorder of the airways that causes recurrent episodes of wheezing, breathlessness, tightness of the chest, and coughing, especially at night or in the morning. These symptoms usually are associated with impaired lung function, frequent use of rescue medication, nighttime symptoms, hospital admissions, near fatal episodes, and limitation of daily activities. ${ }^{1}$ Patients with more than a mild form of asthma require daily prophylactic asthma medications to reverse airway inflammation and control the asthma severity. ${ }^{2}$ The estimated prevalence of asthma among children up to 14 years old in Malaysia is $4.5 \% .^{3}$

Nonadherence to treatment is one important factor in poor asthma control. ${ }^{4}$ Asthmatic children with uncontrolled asthma are more likely to be hospitalized for
Correspondence: Noraida Mohamed Shah Faculty of Pharmacy, Universiti

Kebangsaan Malaysia, Jalan Raja Muda Abdul Aziz, 50300 Kuala Lumpur, Malaysia Tel +60392897199

Fax +60392897090

Email noraida_mohamedshah@yahoo.com 
asthma and require mechanical ventilation, and are at greater risk for recurrent hospitalization than are children whose asthma is well controlled. ${ }^{5}$ The nonadherence rate to asthma treatments has been reported to be as high as 75\% in some European countries and is recognized as the main cause of poor asthma control. ${ }^{6}$

Although treatment adherence is recognized as crucial in the management of children with chronic illnesses, the tools used by clinicians to identify adherence in asthmatic children are limited. Pharmacy databases are increasingly being used to assess medication usage, and a number of measures have been developed to characterize both the intensity of medication usage via intended use (adherence), and the extent to which such usage persists over time (persistence). ${ }^{7}$ Information on prescription refills obtained from computerized pharmacy prescription records gives an indication of the level of adherence over a specific time frame, assuming that the patient consumes the dispensed medication and does not obtain the medication at a nonrecording pharmacy. ${ }^{8,9}$

However, there is lack of uniformity in the definitions used to describe the concepts of medication adherence or persistence. Medication adherence generally refers to the act of conforming to recommendations made by the health care provider, with respect to the timing and frequency of taking medication as well as the dosage. ${ }^{10}$ In retrospective studies, medication adherence can be measured as the number of doses dispensed in relation to the dispensing period and characterized by the medication possession ratio (MPR). The MPR measurement determines patient adherence with a cutoff point of $80 \%$ of medication refilled. On the other hand, persistence is defined as continuing to take any amount of the medication. Assessing persistence is practical for use in both prospective and retrospective studies because it measures from the treatment initiation point to the end of the observation period. An analysis of persistence is typically based on the number of days allowed between refills, considered the "permissible gap," and is characterized by the continuous measure of gaps (CMG).$^{10}$

Controlled asthma is characterized by minimal or no symptoms during the day and at night, no asthma attacks, no emergency visits to physicians or hospitals, minimal need for rescue medications, no limitations on physical activities and exercise, nearly normal lung function, and minimal or no medication side effects. ${ }^{11}$ Poor control of asthma may be the result of chronic undertreatment of the disease and greater reliance on the reliever medications for the relief of acute asthma symptoms. ${ }^{4}$ Previous study has shown an association between poor asthma management, frequent hospital admissions, and poor lung function. There is evidence to show that the prevalence and severity of symptoms and rates of hospital admission for children with asthma are increasing in many countries due to nonadherence to prescribed medications. ${ }^{12}$ Furthermore, the relatively high admission and readmission rates for children with asthma are a concern. ${ }^{13}$

The primary aim of this study was to retrospectively review pharmacy refills of preventive medications in asthmatic children and use the calculated MPR and CMG to determine medication adherence and persistence, respectively. Demographic data, including age, sex, and ethnicity, together with the presence of comorbidities, number of preventive medications, and duration of asthma diagnoses were investigated to identify predictors of nonadherence.

\section{Methodology}

This study was a nonexperimental, retrospective study conducted at the Universiti Kebangsaaan Malaysia Medical Centre (UKMMC), Kuala Lampur, Malaysia. The participants included asthmatic children who were outpatients at the Pediatric Clinic 2 at UKMMC from January 1 to December 31, 2011. This study was approved by the Research Ethics Committee of UKMMC (UKM 1.5.3.5/244/NF-029-2012).

\section{Patient selection criteria}

The inclusion criteria for patients in the present study were as follows: age of less than or equal to 18 years; primary diagnosis of bronchial asthma in a medical or outpatient claims file; history of asthma for at least 1 year; attended the outpatient Pediatric Clinic at UKMMC; had at least one prescription of any preventive medication refilled within the 1-year period from January until December 2011. These patients were excluded: patients with incomplete dispensing or medical data; patients with asthma diagnosed as a secondary disease; patients who were hospitalized most of the time.

\section{Sampling methods}

This was a retrospective observational study, with convenience sampling used in the patient selection process. The data collection occurred in two phases: first, data regarding prescription dispensing were collected at the outpatient pharmacy department, and second, data from medical records were obtained from the Medical Records department at UKMMC.

\section{Research instruments}

\section{Patient medical record}

The patient data were collected and recorded using a data collection form. The collected demographic data included age, 
sex, and ethnicity. The clinical data included disease duration, type of preventive medications, number of preventive medications, disease severity, and the presence of comorbidities.

The data collected regarding medications were based on the types of preventive medications prescribed to asthmatic children, with reference to the UKMMC's Drug Formulary. Among the types of preventive medications collected from the pharmacy dispensing database were corticosteroids: budesonide (Pulmicort ${ }^{\circledR}$ [AstraZeneca, London, UK], Giona ${ }^{\circledR}$ Easyhaler [Orion Corp, Espoo, Finland]), beclomethasone dipropionate (Becotide ${ }^{\circledR}$ Evohaler [GlaxoSmithKline, Inc, Brentford, UK], Beclomet Easyhaler ${ }^{\circledR}$ [Orion Corp]), and ciclesonide (Alvesco ${ }^{\circledR}$ [Takeda Pharmaceuticals International GmbH, Zurich, Switzerland]); leukotriene receptor antagonist: montelukast (Singulair ${ }^{\circledR}$ [Merck and Co, Inc, Whitehouse Station, NJ, USA]); and combination therapy: fluticasone plus salmeterol (Seretide ${ }^{\circledR}$ [GlaxoSmithKline, Inc]), budesonide plus formoterol (Symbicort ${ }^{\circledR}$ [AstraZeneca]), ipratropium plus fenoterol (Berodual- $\mathrm{N}^{\circledR}$ [Boehringer Ingelheim Gmbh, Ingelheim, Germany]), and ipratropium plus salbutamol (Combivent $^{\circledR}$ [Boehringer Ingelheim Gmbh]).

\section{Medication refill records}

Adherence to preventive asthma medications was assessed by measuring refill behavior to calculate the adherence and persistence. The refill adherence was measured using the MPR. MPR determines the number of skipped doses and the discontinuation of medications by assessing medication availability, based on the following equation: ${ }^{14}$

$$
\text { MPR }=\frac{\begin{array}{c}
\text { Sum of the day's supply for all claims } \\
\text { during the study period }
\end{array}}{\begin{array}{l}
\text { Total number of days elapsed during that period } \\
\times 100 \%
\end{array}}
$$

MPR does not address medication overuse; therefore, the resulting value may exceed $100 \%{ }^{15}$

Medication persistence was measured using the $\mathrm{CMG}$, which quantifies the gaps between prescription refills over multiple refill intervals, calculated as follows: ${ }^{16}$

$$
\begin{aligned}
\mathrm{CMG}= & \frac{\text { Number of days without a day's supply }}{\text { Total number of days between the first }} \\
& \times 100 \% .
\end{aligned}
$$

Computation of the CMG takes oversupply into account, therefore, the resulting value cannot exceed $1 .{ }^{16}$ The MPR and $\mathrm{CMG}$ are both indirect measures that indicate overall patient adherence. The data regarding medication refills and dispensing were collected from the pharmacy dispensing database in the outpatient department (OPD).

\section{Statistical analysis}

Analyses of the demographic and clinical data were conducted using descriptive analysis. The adherence results were analyzed as MPR and CMG, both in categories and as continuous measures. The patients were classified as adherent when the MPR was $\geq 80 \%$ and nonadherent when the MPR was $<80 \%$. Likewise, patients with a CMG of $\leq 20 \%$ were considered persistent, whereas a CMG of $>20 \%$ indicated nonpersistence. ${ }^{17}$ Using McNemar's test, we then analyzed an independent model of the association between MPR and CMG; further analysis was conducted using the kappa coefficient $(\kappa)$.

Demographic (age, sex, and ethnicity) and clinical data (comorbidities, number of preventive medications, and duration of asthma diagnosis) were included as independent factors in a logistic regression, to determine the significant predictors for adherence (MPR) and persistence (CMG). Odds ratios (ORs) and 95\% confidence intervals (CIs) were calculated for this regression.

SPSS (SPSS Inc. PASW Statistics for Windows, Version 18.0 [2009]; Chicago, IL, USA) was used for analyses. All reported $P$-values were two-sided, with $P<0.05$ considered statistically significant.

\section{Results}

\section{Patient characteristics}

A total of 550 subjects were identified from the UKMMC pharmacy database as having preventive medications refilled within the study period (January 1, 2011-December 31, 2011). Of these, 373 subjects who fulfilled the inclusion criteria were randomly selected. Finally, 155 subjects who only filled their prescription once (ie, no refill prescription) were excluded from the study, leaving 218 participants in the sample of data to be analyzed. The corticosteroid inhalers were the most frequently refilled medication (44.3\%), followed by the leukotriene receptor antagonists (22.3\%). The mean (standard deviation [SD]) age of subjects was 8.05 (3.9) years, and more than half $(58.7 \%)$ were male. A majority of subjects were Malays (83.5\%). A total of 147 (67.4\%) subjects had a family history of bronchial asthma. The mean number of comorbidities was 1.17 (1.0). The mean duration of asthma was 5.02 (2.9) years, and an average of 1.3 (0.5) types of preventive medications were prescribed for each patient. The characteristics of the study population are summarized in Table 1. 
Table I Characteristics of study sample $(n=2 / 8)$

\begin{tabular}{|c|c|c|}
\hline \multirow{2}{*}{$\begin{array}{l}\text { Characteristics } \\
(n=2 \mid 8)\end{array}$} & \multicolumn{2}{|l|}{ Findings } \\
\hline & $\begin{array}{l}\text { Frequency, } \\
\text { n (\%) }\end{array}$ & Mean \pm SD \\
\hline Age (years) & & $8.05 \pm 3.93$ \\
\hline $1-6$ & $84(38.5)$ & \\
\hline $7-12$ & $100(45.9)$ & \\
\hline $13-18$ & $34(15.6)$ & \\
\hline \multicolumn{3}{|l|}{ Sex } \\
\hline Male & $128(58.7)$ & \\
\hline Female & $90(4 I .3)$ & \\
\hline \multicolumn{3}{|l|}{ Ethnicity } \\
\hline Malay & $182(83.5)$ & \\
\hline Chinese & $19(8.7)$ & \\
\hline Indian & $13(6.0)$ & \\
\hline Others & $4(1.8)$ & \\
\hline \multicolumn{3}{|l|}{ Comorbidities } \\
\hline \multicolumn{3}{|l|}{ Presence of comorbidity } \\
\hline Yes & $159(72.9)$ & \\
\hline No & $59(27.1)$ & \\
\hline Total number & 251 & $1.17 \pm 1.00$ \\
\hline Allergy rhinitis & $74(29.5)$ & per patient \\
\hline Eczema & $46(18.3)$ & \\
\hline Obesity & $22(8.8)$ & \\
\hline Allergy & $5(2.0)$ & \\
\hline Acute bronchitis & $4(1.6)$ & \\
\hline Pneumonia & $2(<1)$ & \\
\hline Others & $98(39.0)$ & \\
\hline \multicolumn{3}{|l|}{ Family background of asthma } \\
\hline Yes & 147 (67.4) & \\
\hline No & $63(28.9)$ & \\
\hline Adopted & $8(3.7)$ & \\
\hline \multicolumn{3}{|l|}{ Duration of asthma diagnosis (years) } \\
\hline $1-6$ & $\mathrm{II} 2(5 \mathrm{I} .4)$ & $5.02 \pm 2.90$ \\
\hline $7-12$ & $91(4 \mid .7)$ & \\
\hline $13-18$ & $15(6.9)$ & \\
\hline \multicolumn{3}{|l|}{ Preventive medications refilled } \\
\hline Total number & 294 & $1.30 \pm 0.46$ \\
\hline \multicolumn{3}{|l|}{ Type of preventive medications } \\
\hline Budesonide (Pulmicort ${ }^{\circledR}$ ) & $127(44.3)$ & \\
\hline Montelukast (Singulair $\left.{ }^{\circledR}\right)$ & $64(22.3)$ & \\
\hline Ciclesonide $\left(\right.$ Alvesco ${ }^{\circledR}$ ) & $31(10.8)$ & \\
\hline \multicolumn{2}{|l|}{$\left(\right.$ Seretide $\left.{ }^{\circledR} 25 / 125\right)$} & \\
\hline Budesonide (Giona ${ }^{\circledR}$ Easyhaler) & $24(8.4)$ & \\
\hline Beclomethasone & $4(1.4)$ & \\
\hline \multicolumn{3}{|l|}{ (Becotide ${ }^{\circledR}$ Evohaler) } \\
\hline Beclomethasone & $4(1.4)$ & \\
\hline \multicolumn{3}{|l|}{$\left(\right.$ Beclomet Easyhaler $\left.^{\circledR}\right)$} \\
\hline Others & $2(<1)$ & \\
\hline
\end{tabular}

Notes: Budesonide (Pulmicort ${ }^{\circledR}$ [AstraZeneca, London, UK], Giona ${ }^{\circledR}$ Easyhaler [Orion Corp, Espoo, Finland]), beclomethasone dipropionate (Becotide ${ }^{\circledR}$ Evohaler [GlaxoSmithKline, Inc, Brentford, UK], Beclomet Easyhaler ${ }^{\circledR}$ [Orion Corp]), ciclesonide (Alvesco ${ }^{\circledR}$ [Takeda Pharmaceuticals International GmbH, Zurich, Switzerland]), montelukast (Singulair ${ }^{\circledR}$ [Merck and Co, Inc, Whitehouse Station, N], USA]), fluticasone + salmeterol (Seretide ${ }^{\circledast}$ [GlaxoSmithKline, Inc]).

Abbreviation: SD, standard deviation.

\section{Prevalence of nonadherence}

Overall, adherence was poor, with only $38.1 \%$ of the subjects having an MPR of $\geq 80 \%$. Multiple termination gaps within the study period were discovered, and based on the CMG scores, only $27.5 \%$ of the subjects were persistent with their medication.

\section{Relationship between adherence and persistence}

The relationship between adherence and persistence was explored through McNemar's test, as shown in Table 2. Our findings suggest that refill adherence was significantly different from refill persistence, and the relationship between adherence and persistence was weak $(P<0.001 ; \kappa=0.379)$.

\section{Predictors of medication adherence and persistence}

A binary logistic regression was performed to determine factors that may influence adherence and persistence. It was found that age, sex, ethnicity, number of preventive medications refilled, and the duration of the asthma diagnosis were not significant predictors of adherence or persistence. Only the presence of comorbidities was found to significantly influence adherence and persistence (OR 16.2, 95\% CI: 7.76-33.84 and OR 2.6, 95\% CI: 0.134-52.79, respectively $[P<0.001])$, as shown in Tables 3 and 4.

\section{Discussion}

In this study, only $38.1 \%$ (or 83 of 218 children with asthma) were adherent to the preventive medications, based on a score of MPR $\geq 80 \%$. This is consistent with previous research, in which $15 \%-39 \%$ of asthmatic children aged $0-18$ years were adherent to the use of controller medications. ${ }^{18}$ It has been suggested that low adherence among children with asthma may be due to parental inability to take time off from work to attend appointments and refill their child's medications. ${ }^{19}$ In addition, Dawood et al mentioned that, in general, poor adherence in children can be attributed to the parental lack of understanding about the diagnosis and drug therapy effectiveness as well as fear of medication side effects. ${ }^{20}$

We also observed a relatively low level of persistence (27.5\%). Previous research regarding persistence with asthma inhaler medications discovered that poor persistence among children was associated with their incomplete understanding of the mechanism of action of their preventive medicines, thus causing them to stop the medications when they felt better rather than using them as intended. ${ }^{21}$ It also has been reported that children will stop using medication when they think the treatment has not helped improve their asthma over a long period, even when the actual reason for poor treatment response could be due to improper use of the medication (eg, poor inhalation technique). ${ }^{22}$ 
Table 2 Association of two pharmacy refill measures (MPR and CMG)

\begin{tabular}{lllll}
\hline Total $(\mathbf{n = 2 1 8 )}$ & MPR & & $\begin{array}{l}\text { McNemar's test of } \chi^{2} \\
\text { 2-tailed test } \\
\text { P-value }\end{array}$ & $\begin{array}{l}\text { Measure of } \\
\text { agreement } \boldsymbol{\kappa}\end{array}$ \\
\hline CMG & $\begin{array}{l}\text { Nonadherence } \\
\mathbf{( < 8 0 \% )}\end{array}$ & $\begin{array}{l}\text { Adherence } \\
\mathbf{( \geq 8 0 \% )}\end{array}$ & $<0.001 *$ & 0.397 \\
Persistent $\leq 20 \%$ & $60(27.5 \%)$ & $0(0 \%)$ & \\
Nonpersistent $>20 \%$ & $75(34.4 \%)$ & $83(38.1 \%)$ & \\
\hline
\end{tabular}

Notes: The values are presented as patient mean (percentage). $* P<0.05$.

Abbreviations: CMG, continuous measure of gaps; MPR, medication possession ratio.

The relationship between adherence and persistence was found to be significant $(P<0.001)$ but weak $(\kappa=0.379)$ (a kappa value of between 0.21 and 0.40 is classified as fair agreement). ${ }^{23} \mathrm{~A}$ total of $65.6 \%$ patients had dissimilar classifications of adherence and persistence. Only 34.4\% of patients in this study were classified as nonadherent and nonpersistent (Table 2). This could be explained by the fact that adherence and persistence measure different aspects of medication-taking behavior. MPR is defined by the "number of doses dispensed in relation to the dispensing period," whereas $\mathrm{CMG}$ is defined as the "duration of time from initiation to the discontinuation of therapy." ${ }^{10}$ Hence, patients may be refilling the prescriptions regularly but may not be persistent in taking their medicines.

This is consistent with results of a study by Lee et al, which demonstrated that medication adherence was significantly and positively associated with persistence, according to data from pharmacy claims system. ${ }^{24}$ Elliot et al studied medication adherence and persistence from an economic perspective, stating that both are consistently affected by age, experiences, and side effects and furthermore, that these relationships change over time. ${ }^{25}$

\section{Predictors of adherence}

The possible predisposing characteristics assessed in this study were age, ethnicity, sex, the presence of comorbidities, duration of the asthma diagnosis, and the number of preventive medications refilled. We found that child age was not a significant pre-

Table 3 Factors in the logistic regression analysis models that are independently linked to adherence

\begin{tabular}{|c|c|c|c|c|c|c|}
\hline \multirow[t]{2}{*}{ Parameter } & \multirow{2}{*}{$\begin{array}{l}\text { Log } \\
\text { odds } \\
\text { (B) }\end{array}$} & \multirow[t]{2}{*}{ SE } & \multirow{2}{*}{$\begin{array}{l}\text { 2-tailed } \\
\text { test } \\
P \text {-value }\end{array}$} & \multirow[t]{2}{*}{ OR } & \multicolumn{2}{|l|}{$95 \% \mathrm{Cl}$} \\
\hline & & & & & Lower & Upper \\
\hline \multicolumn{7}{|c|}{ Presence of comorbidities } \\
\hline $\begin{array}{l}\text { Yes } \\
\text { No }\end{array}$ & 2.786 & 0.376 & $<0.00 I^{*}$ & 16.209 & 7.763 & 33.844 \\
\hline
\end{tabular}

Notes: Dependent variable coding: MPR $<80 \%$ (nonadherence) $=0 ;$ MPR $\geq 80 \%$ (adherence) $=I$. $* P<0.05$; B - regression coefficient.

Abbreviations: $\mathrm{Cl}$, confidence interval; MPR, medication possession ratio; $\mathrm{OR}$, odds ratio; $\mathrm{SE}$, standard error. dictor of adherence or persistence, consistent with the results of a study by Lindberg et al. ${ }^{26}$ However, other studies have found an association between child age and adherence levels. ${ }^{27,28}$ While parents are fully responsible for administering medications to their young children, this is not the case for adolescents. ${ }^{29}$ Adolescents are driven by the need for peer acceptance, rather than parental control, and adherence to a medication regimen may place them at risk of being different from others. ${ }^{30}$

We also found no association between participant sex and adherence or persistence levels. Similar results were noted in studies by Bae et al and Vic et al; however, Balbay et al found that males had poorer adherence and persistence levels compared with females. ${ }^{31-33}$ Conversely, Elkout et al discovered higher adherence rates in males than in females. Thus, the association between sex and adherence remains unclear. ${ }^{18}$

In the present study, we also found no significant relationship between ethnicity and adherence or persistence levels. Malaysian citizens consist of the ethnic groups Malays (63.1\%), Chinese (24.6\%), Indians (7.3\%), and others (5\%). ${ }^{34}$ Therefore, the ethnic composition may not have been represented in a similar proportion in this study, as shown in Table 1, and may have affected the findings. Nsouli suggested that there is a relationship between treatment adherence and race, and that the low socioeconomic status and the language barriers of the minority races in the countries investigated resulted in poorer adherence. ${ }^{35}$ However, Jin et al concluded that race may not be a true predictive factor of poor adherence, due to the inconsistent results in the research literature. ${ }^{36}$

Table 4 Factors in the logistic regression analysis models that are independently linked to nonpersistence

\begin{tabular}{lllllll}
\hline Parameter & $\begin{array}{l}\text { Log } \\
\text { odds } \\
\text { (B) }\end{array}$ & $\begin{array}{l}\text { 2-tailed } \\
\text { test } \\
\text { P-value }\end{array}$ & OR & & 95\% Cl & \\
\cline { 6 - 7 } & & Lower & Upper \\
\hline $\begin{array}{l}\text { Presence of comorbidities } \\
\text { Yes }\end{array} \quad 0.968$ & 1.520 & $<0.00 I^{*}$ & 2.633 & 0.134 & 52.79 \\
No & & & & & \\
(Reference category: No comorbidities) & & & \\
\hline
\end{tabular}

Notes: Dependent variable coding: CMG $\leq 20 \%$ (persistence) $=0$; CMG $>20 \%$ (nonpersistence) $=\mathrm{I}$. $* P<0.05$.

Abbreviations: $\mathrm{Cl}$, confidence interval; CMG, continuous measure of gaps; OR, odds ratio; SE, standard error. 
Furthermore, the duration of asthma diagnosis had no association with adherence or persistence levels. According to a study by Singh et al, longer disease durations may motivate patients to search for complementary therapies as "magic cures," due to the perception that the lack of improvement in their asthma symptoms is due to the ineffectiveness of their current treatment. ${ }^{37}$ To the contrary, Latty et al studied adherence to asthma inhalers and leukotriene receptor antagonists and found that 12-month persistence rates were lower in new medications users $(1.5 \%-6 \%)$ than in chronic medication users (27\%-44\%). ${ }^{38}$ This suggests that perhaps, after years of suffering from asthma, patients may be more likely to accept and follow prescribed treatment regimens. ${ }^{36}$

Inhaled corticosteroids were the most commonly prescribed preventive medications in our study, which is to be expected - they are generally a first-line maintenance therapy because of their significant improvement in asthma control. ${ }^{39}$ However, our results suggest no association between the number of prescribed preventive medications and adherence or persistence levels. This is in contrast to Joseph et al, who found that the number of medications prescribed played a significant role in medication adherence and persistence. ${ }^{40}$ When patients need to consume many medications at once, they will weigh potential risks against the benefits. Consequently, they may hesitate or be nonadherent to their prescribed medications when their perceived risks outweigh the perceived benefits. ${ }^{41}$ No association was found for this variable, possibly due to the fact that only the number of preventive medications and not the total number of prescribed medications were analyzed as a possible predictor of nonadherence in the present study.

Presence of comorbidities was the only factor significantly associated with adherence and persistence levels among children with asthma in this study. However, the data suggested two different directions of association: the presence of comorbidity reduced the risk of nonadherence but increased the risk of nonpersistence. Boulet found that comorbidities were associated with uncontrolled asthma. ${ }^{42}$ The presence of comorbidities may worsen asthma severity, thus making asthma control more difficult to achieve. Children's behavior regarding asthma medications may also change when they have comorbid illness. ${ }^{42}$ Furthermore, fluctuations in asthma control and the frequent presentation of asthma symptoms in patients with comorbidities can result in the perception of ineffective treatment. ${ }^{43}$ Consequently, children tend to discontinue medications themselves, resulting in low persistence levels.

\section{Study limitations}

The present study only collected data for a 1-year period, which was rather short, and results might differ if adherence and persistence were examined for a longer time frame. Furthermore, the sample size was relatively small, although larger than many other studies in this area. This may have resulted in a reduced number of predictors that could potentially influence adherence in this population. Estimating prescription refill adherence via a pharmacy database may not reflect the actual prescribing and dispensing of medications or the use of these medications by the children themselves. It is also assumed that the patients did not obtain their medications at other pharmacies, which we believe was the case for the majority of patients in this study. This is because the payment at the hospital is fixed at RM40 (US\$12.16) per patient for each clinic visit, inclusive of all medications prescribed that are listed in the hospital's formulary (this is the case for all the asthma preventive medications mentioned in this study). However, medication is free for government employees and their dependants at the study site (UKMMC) and all other government hospitals. The nature of the study, being retrospective, is also a limitation, and it was also assumed that the pharmacy kept a good and reliable database for the medication refills of all patients. Future studies would benefit from including a larger sample size and measuring adherence, at various time points, for more than a 1-year period.

\section{Conclusion}

Asthmatic children at the UKMMC had poor adherence and persistence to preventive asthma medications. Presence of comorbidities was the only factor found to significantly predict medication adherence in children with asthma. Proper evaluation and management of comorbid conditions among asthmatic children is essential to achieve better adherence to medication and better control of the disease.

\section{Acknowledgments}

The authors would like to thank the pharmacy staff at the UKMMC for access to the pharmacy's computerized dispensing database. In addition, we give special thanks to the hospital Medical Records staff for their help in retrieving medical records.

\section{Disclosure}

There was no funding received for this research. The authors report no conflicts of interest in this work. 


\section{References}

1. Boulet LP, Becker A, Bérubé D, Beveridge R, Ernst P. [Summary of the recommendations of the Canadian Consensus Conference on Asthma 1999. Canadian Asthma Consensus Group]. CMAJ. 1999;161(11 Suppl Resume):SF1-SF14. French.

2. Sheffer AL, Bousquet J, Busse WW, et al. International consensus report on diagnosis and treatment of asthma. Eur Respir J. 1992;5(5): 601-641.

3. thestar.com.my [homepage on the Internet]. Improving asthma control. Star Publications; 2011 [updated September 13, 2013]. Available from: http://www.thestar.com.my/Lifestyle/Health/2011/05/29/Improvingasthma-control.aspx. Accessed December 15, 2013.

4. World Health Organization. Adherence to Long-Term Therapies. Evidence for Action. Geneva: World Health Organization; 2003. Available from: http://www.emro.who.int/ncd/Publications/adherence_ report.pdf. Accessed October 23, 2013.

5. Ferris TG, Crain EF, Oken E, Wang L, Clark S, Camargo CA Jr; MARC (Multicenter Airway Research Collaboration) Investigators. Insurance and quality of care for children with acute asthma. Ambul Pediatr. 2001;1(5):267-274.

6. Cerveri I, Locatelli F, Zoia MC, Corsico A, Accordini S, de Marco R. International variations in asthma treatment compliance: the results of the European Community Respiratory Health Survey (ECRHS). Eur Respir J. 1999;14(2):288-294.

7. Vander Stichele R. Measurement of patient compliance and the interpretation of randomized clinical trials. Eur J Clin Pharmacol. 1991;41(1):27-35.

8. Nichols-English G, Poirier S. Optimizing adherence to pharmaceutical care plans. J Am Pharm (Wash). 2000;40(4):475-485.

9. Nunes V, Neilson J, O’Flynn N, et al. Clinical Guidelines and Evidence Review for Medicines Adherence: Involving Patients in Decisions About Prescribed Medicines and Supporting Adherence. London: National Collaborating Centre for Primary Care and Royal College of General Practitioners; 2009. Available from: http://www.nice.org.uk/nicemedia/ pdf/CG76FullGuideline.pdf. Accessed November 20, 2011.

10. Cramer JA, Roy A, Burrell A, et al. Medication compliance and persistence: terminology and definitions. Value Health. 2008;11(1): 44-47.

11. British Thoracic Society; Scottish Intercollegiate Guidelines Network. British guideline on the management of asthma. Thorax. 2003; 58(Suppl 1):i1-i94.

12. Kun HY, Oates RK, Mellis CM. Hospital admissions and attendances for asthma - a true increase? Med J Aust. 1993;159(5):312-313.

13. Martin AJ, Campbell DA, Gluyas PA, et al. Characteristics of near-fatal asthma in childhood. Pediatr Pulmonol. 1995;20(1):1-8.

14. Fairman K, Motheral B. Evaluating medication adherence: which measure is right for your program? J Managed Care Pharm. 2000;6(6):499-504.

15. Vink NM, Klungel OH, Stolk RP, Denig P. Comparison of various measures for assessing medication refill adherence using prescription data. Pharmacoepidemiol Drug Saf. 2009;18(2):159-165.

16. Latry P, Pinet M, Labat A, et al. Adherence to anti-inflammatory treatment for asthma in clinical practice in France. Clin Ther. 2008;30 Spec No:1058-1068.

17. Krousel-Wood M, Islam T, Webber LS, Re RN, Morisky DE, Muntner P. New medication adherence scale versus pharmacy refill rates in seniors with hypertension. Am J Manag Care. 2009;15(1): 59-66.

18. Elkout H, Helms PJ, Simpson CR, McLay JS. Adequate levels of adherence with controller medication is associated with increased use of rescue medication in asthmatic children. PLoS One. 2012;7(6): e39130.

19. Major DA. Utilizing role theory to help employed parents cope with children's chronic illness. Health Educ Res. 2003;18(1):45-57.

20. Dawood OT, Mohamed Ibrahim MI, Palaian S. Medication compliance among children. World J Pediatr. 2010;6(3):3:1-3.

21. Tavasoli S, Heidarnazhad H, Kazemnejad A. Factors affecting patients' compliance to metered-dose inhaler drugs in two asthma clinics in Tehran, Iran. Iran J Allergy Asthma Immunol. 2006;5(4):187-193.
22. Restrepo RD, Alvarez MT, Wittnebel LD, et al. Medication adherence issues in patients treated for COPD. Int J Chron Obstruct Pulmon Dis. 2008;3(3):371-384.

23. Landis JR, Koch GG. The measurement of observer agreement for categorical data. Biometrics. 1977;33(1):159-174.

24. Lee JK, Grace KA, Taylor AJ. Effect of a pharmacy care program on medication adherence and persistence, blood pressure, and lowdensity lipoprotein cholesterol: a randomized controlled trial. JAMA. 2006;296(21):2563-2571.

25. Elliott RA, Shinogle JA, Peele P, Bhosle M, Hughes DA. Understanding medication compliance and persistence from an economics perspective. Value Health. 2008;11(4):600-610.

26. Lindberg M, Ekström T, Möller M, Ahlner J. Asthma care and factors affecting medication compliance: the patient's point of view. Int J Qual Health Care. 2001;13(5):375-383.

27. Rogers T and Simmons J. Medication persistence and health care expenditures in a managed Medicaid population with asthma. Drug Benefit Trends. 2009. Available at: http://www.consultantlive.com/ articles/medication-persistence-and-health-care-expenditures-managedmedicaid-population-asthma. Accessed January 8, 2014.

28. Williams LK, Pladevall M, Xi H, et al. Relationship between adherence to inhaled corticosteroids and poor outcomes among adults with asthma. J Allergy Clin Immunol. 2004;114(6):1288-1293.

29. Van Ganse E, Mörk AC, Osman LM, et al. Factors affecting adherence to asthma treatment: patient and physician perspectives. Prim Care Resp J. 2003;12(2):46-51.

30. Kyngas HA, Kroll T, Duffy ME. Compliance in adolescent with chronic disease: a review. J Adolesc Health. 2000;26:379-388.

31. Bae YJ, Kim TB, Jee YK, et al. Severe asthma patients in Korea overestimate their adherence to inhaled corticorsteroids. J Asthma. 2009;46(6):591-595.

32. Vik SA, Maxwell CJ, Hogan DB. Measurement, correlates, and health outcomes of medication adherence among seniors. Ann Pharmacother. 2004;38(2):303-312.

33. Balbay O, Annakkaya AN, Arbak P, Bilgin C, Erbas M. Which patients are able to adhere to tuberculosis treatment? A study in a rural area in the northwest part of Turkey. Jpn J Infect Dis. 2005;58(3):152-158.

34. statistics.gov.my [homepage on the Internet]. Population distribution and basic demographic characteristic report 2010. Department of Statistics Malaysia; 2010 [updated December 13, 2013; cited November 20, 2011]. Available from: http://www.statistics.gov. my/portal/index.php?option=com_content\&id=1215. Accessed December 15, 2013.

35. Nsouli TM. Inner-city disadvantaged populations and asthma prevalence, morbidity, and mortality. Ann Allergy Asthma Immunol. 1999;82(1):2-4.

36. Jin J, Sklar GE, Min Sen Oh V, Chuen Li S. Factors affecting therapeutic compliance: A review from the patient's perspective. Ther Clin Risk Manag. 2008;4(1):269-286.

37. Singh V, Sinha HV, Gupta R. Barriers in the management of asthma and attitudes towards complementary medicine. Respir Med. 2002;96(10):835-840.

38. Latty P, Pinet M, Labat A, et al. Adherence to anti-inflammatory treatment for asthma in clinical practice in France. Clin Ther. 2008;30 Spec No:1058-1068.

39. Verona E, Petrov D, Cserhati E, et al. Fluticasone propionate in asthma: a long term dose comparison study. Arch Dis Child. 2003;88(6):503-509.

40. Rau JL. Determinants of patient adherence to an aerosol regimen. Respir Care. 2005;50(10):1346-1356; discussion 1357-1359.

41. Clark N, Jones P, Keller S, Vermeire P. Patient factors and compliance with asthma therapy. Respir Med. 1999;93(12):856-862.

42. Boulet LP. Influence of comorbid conditions on asthma. Eur Respir J. 2009;33(4):897-906.

43. Horne R, Price D, Cleland J, et al. Can asthma control be improved by understanding the patient's perspective? BMC Pulm Med. 2007;7:8. 


\section{Publish your work in this journal}

Patient Preference and Adherence is an international, peer-reviewed, open access journal focusing on the growing importance of patient preference and adherence throughout the therapeutic continuum. Patient satisfaction, acceptability, quality of life, compliance, persistence and their role in developing new therapeutic modalities and compounds to

optimize clinical outcomes for existing disease states are major areas of interest. This journal has been accepted for indexing on PubMed Central. The manuscript management system is completely online and includes a very quick and fair peer-review system. Visit http://www.dovepress.com/ testimonials.php to read real quotes from published authors.

Submit your manuscript here: http://www.dovepress.com/patient-preference-and-adherence-journal 